\title{
Antiseptic effect of sea cucumber (Holothuria atra) against multi-organ failure induced by sepsis: Molecular and histopathological study
}

\author{
DALIA Y.SAAD ${ }^{1,2}$, AHMED A. BAIOMY ${ }^{1,3}$ and AHMED A. MANSOUR ${ }^{3,4}$ \\ ${ }^{1}$ Department of Zoology, Faculty of Science, Cairo University, Giza 12613, Egypt; Departments of ${ }^{2}$ Medical Laboratory, and \\ ${ }^{3}$ Medical Biotechnology, Faculty of Applied Medical Sciences, Taif University, Taif 11942, Saudi Arabia; \\ ${ }^{4}$ Department of Genetics, Faculty of Agriculture, Ain Shams University, Cairo 11241, Egypt
}

Received December 1, 2015; Accepted March 10, 2016

DOI: $10.3892 /$ etm.2016.3321

\begin{abstract}
Sepsis is a systemic inflammatory response to infection and severe sepsis patients can develop acute lung and liver injury. The aim of the present study was to evaluate the efficacy of Holothuria atra methanolic body wall extract (HaE), as an antioxidant and anti-inflammatory agent against induced sepsis in a cecal ligation and puncture (CLP) rat model. In total, 30 males albino rats were divided into three groups ( $n=10$ each) as follows: Sham (Sh), which was used as negative control; sepsis (Se), which was used as a positive control and was subjected to CLP surgery; and Ho, which was subjected to CLP and fed with $200 \mathrm{mg} / \mathrm{kg}$ (body weight) of HaE, once daily for 7 days. Subsequently, the expression of various genes was detected by polymerase chain reaction, while liver and lung tissues were examined by immunohistochemistry. The expression of Caspase-3 was significantly reduced in liver and lung tissues in the Ho group, while the expression levels of Gsta2, Cat and Sodl genes were slightly reduced in the Ho group, when compared with the Se group. In addition, expression levels of tumor necrosis factor, interferon- $\gamma$, liver interleukin (IL) $1 \mathrm{~b}$ and lung IL1a were reduced in the Ho group compared with the Se group. Furthermore, histopathological changes were observed in liver tissues of the Se group, including congestion of hepatoportal blood vessel and focal hepatic necrosis, while lung tissues showed marked edema, hemorrhage and alveolar septal thickening. The Ho group showed apparent normal hepatic parenchyma and slight interstitial pneumonia. Immunohistochemical staining of caspase-3 in liver and lung tissues showed no expression in the Sh group, strong expression in the Se group and moderate expression in the Ho group. In conclusion, $\mathrm{HaE}$ demonstrated beneficial effect against
\end{abstract}

Correspondence to: Dr Ahmed A. Baiomy, Department of Zoology, Faculty of Science, Cairo University, Giza Street, Giza 12613, Egypt

E-mail: ahmedbaiomy362@gmail.com

Key words: sepsis, cecal ligation and puncture, rats, sea cucumber, gene expression, histopathology, immunohistochemistry induced sepsis, which may be attributed to its antioxidant and antiapoptotic activities.

\section{Introduction}

Sepsis, one of the main issues encountered in the majority of health care centers, is a life-threatening disease that causes widespread mortality worldwide (1). The mortality rate of uncomplicated sepsis is $25 \%$, increasing to $80 \%$ in patients that proceed to develop multiple organ failure (2). Sepsis is associated with the presence of pathogenic microorganisms or their toxins in the bloodstream. Oxidative stress has been consistently reported in patients with sepsis, and thus antioxidants may be used as a potential therapy (3). However, the effect of antioxidants administrated in septic shock is limited (4); therefore, the expression levels of certain antioxidants (such as the glutathione S-transferases gene family), oxidative stress responsive genes (including oxidases, peroxidases, catalase and superoxide dismutase) or anti-inflammatory genes (such as interleukins) can be detected in the tissues in response to sepsis or any curative treatment $(5,6)$. Oxidative stress is indicated by increased levels of lipid peroxides, direct detection of circulating radicals and decreased antioxidant concentrations (7). Mitochondrial dysfunction resulting from oxidative stress has been suggested to serve a role in the development of multiorgan failure in sepsis, including liver and lung failure $(3,8)$. Approximately $50 \%$ of patients with severe sepsis also develop acute lung injury $(9,10)$. Pericytes in lung tissue have been shown to produce an increase in pro-inflammatory cytokines in response to bacterial lipopolysaccharide (LPS) (11).

Tumour necrosis factor (TNF) and interferon- $\gamma($ IFN- $\gamma$ ) are of particular importance in the development of septic shock (12-15). Therefore, the development of individual sepsis treatments has focused on the regulation of TNF expression $(16,17)$. However, previous clinical trials investigating specific anti-TNF sepsis treatments have demonstrated the complexity of this disease and the involvement of various cytokines with overlapping functions (17). IFN- $\gamma$ is also a crucial regulator of LPS-induced pathology $(18,19)$. Treatment with IFN- $\gamma$ or a neutralizing antibody against IFN- $\gamma$ has been found to alter the lethal outcomes of several types of 
Gram-negative bacterial infections and endotoxic shock (19). IFN- $\gamma$ receptor-deficient mice are relatively resistant to LPS-induced septic shock $(20,21)$.

INF- $\gamma$ serves an important role in the regulation of innate and acquired antimicrobial immunity. The expression of INF- $\gamma$ is regulated by a set of complex interactions between accessory cells, such as macrophages, dendritic cells, $\mathrm{T}$ lymphocytes and natural killer cells $(22,23)$. INF- $\gamma$ amplifies antimicrobial immune responses by stimulating macrophage functions such as phagocytosis, respiratory burst activity, antigen presentation and cytokine secretion $(18,21,24)$. Previous studies have suggested that IFN- $\gamma$ may increase the responsiveness to LPS by altering the signal transduction pathway, in particular through the upregulation of the Toll-like receptor 4 gene expression (25), or promotion of IL-1 receptor-associated kinase expression and its association with myeloid differentiation primary response gene 88 (26).

Despite recent advances in antibiotic therapy, no significant improvements have been accomplished in the treatment of sepsis. Thus, there is an urgent demand for the development of a novel therapy for sepsis management. The increase of antibiotic-resistant pathogenic bacteria has stimulated the search for antimicrobial agents from alternative sources $(27,28)$. Crude extract from the sea cucumber, also known as Holothuria atra (H. atra), contains cytostatic, antifungal, hemolytic, anticancer and antioxidant phenolic compounds, while it also has immunomodulatory effects. This extract has been found to have a potential hepatoprotective activity against thioacetamide-induced liver injury in a rat model (29). In addition, the curative effects of the sea cucumber extract was reported against DMBA-induced hepatorenal diseases in rats $(30,31)$.

Apoptosis, another prominent feature of sepsis, involves a mechanism of closely-regulated disassembly of cells resulting from the activation of caspases, which are specialized proteases. In septic animal models, increased apoptotic cell death has also been reported in parenchymal cells, including intestinal and lung epithelial cells $(32,33)$. Furthermore, in situ localization of cleaved caspase- 3 may have an application in the histological labeling of cells in apoptosis (34). Lysophospholipids from $H$. atra were also shown to inhibit $\mathrm{H}_{2} \mathrm{O}_{2}$-induced apoptosis in macrophages (35).

Cecum ligation and puncture (CLP) is currently the most widely used animal model of sepsis $(36,37)$. In the CLP rat model, autophagy was also induced in multiple organs, including the lung and liver $(38,39)$. In the present study, the potent in vivo efficacy of sea cucumber body wall extract against induced sepsis in a CLP rat model was investigated at molecular and histopathological levels.

\section{Materials and methods}

Sample collection and preparation of $H$. atra extract (HaE). Sea cucumbers ( $H$. atra; $\mathrm{n}=50$ ) were collected from the Thuwal area on Saudi Arabia's Red Sea coast. The taxonomic identity of the samples was confirmed based on the studies of Purcell et al (40). The animals were transported to the Medical Laboratory of Applied Medical Sciences, Taif University, (Turabah, Saudi Arabia), in an ice box. They were rinsed thoroughly, removing any internal organs and body fluids, and then the animals' body wall was soaked in appropriate amounts of methanol-water mixture (50:50) and stirred using a magnetic stirrer for $16 \mathrm{~h}$. The mixture was filtered twice. Finally, the two extracts were pooled together and concentrated in a rotary evaporator during which the extract was evaporated at low pressure in a double boiler at $30^{\circ} \mathrm{C}$ using a LABROTA 4001 efficient (Heidolph Instruments $\mathrm{GmbH} \& \mathrm{Co}$., Schwabach, Germany) to avoid degradation of compounds, for $2 \mathrm{~h}$. The powdered extract was obtained by freeze drying and was stored at $-20^{\circ} \mathrm{C}$ until further use (41).

Animals. All animal procedures were approved by the Ethical Committee Office of the Scientific Dean of Taif University (Taif, Saudi Arabia).

In total, 30 adult male albino rats (Rattus norvegicus; age, 6-8 weeks) weighing 150-170 g were obtained from the King Fahd Research Unit at King Abdulaziz University (Jeddah, Saudi Arabia). The rats were housed in polypropylene cages in an air conditioned room at a temperature of $25 \pm 2{ }^{\circ} \mathrm{C}$ and under natural light cycle. They were fed standard chow pellets and had access to water ad libitum. The rats were kept for 1 week for acclimatization and then divided into three groups (10 animals in each) as follows: Sham (Sh) group, which was used as a negative control (received distilled water and underwent surgery along with cecal manipulations, but without ligation and puncture); sepsis (Se) group, which was surgically subjected to CLP [sepsis was achieved in rats by cecal ligation at a point $\sim 1 \mathrm{~cm}$ from the cecal tip and punctured with a 20-gauge needle (36)], and was used as positive control; and the Ho group, in which animals were subjected to CLP and orally administered $200 \mathrm{mg} / \mathrm{kg}$ body weight HaE, once daily for 7 days. All groups were handled under sterile and antiseptic conditions. All animals were sacrificed by inhalation of diethyl ether, and dissected after 7 days. The animals were observed daily subsequent to the surgery. The mortality rate was calculated in all groups after the incidence of the initial case of mortality. The death rate was scored each day for 7 days until the end of the experiment. The mortality rate was presented as a percentage.

The rat organs (liver and lung) were collected and applied for RNA extraction and histopathological examinations.

Mortality rate study. Following CLP surgery, the mortality rate and symptoms of sepsis were calculated over the subsequent 7 days for the 3 experimental groups. Rat mortality was recorded every $24 \mathrm{~h}$ until the 7 th day and is expressed as a percentage.

RNA extraction and quantification. Total RNA was extracted from the liver and lungs of all rat groups according to the method described by Attia et al (42). RNA samples were diluted in diethylpyrocarbonate water to $40 \mu \mathrm{g} / \mathrm{ml}$ according to spectroscopy quantification using a Bio-Rad SmartSpec Plus UV/Visible Spectrophotometer (Bio-Rad Laboratories, Inc., Hercules, CA, USA).

Primers. All primers were designed (based on the gene sequences published in the GenBank database) using the Primer3Plus online software (http://primer3plus.com/). The primers were manufactured by Bioron $\mathrm{GmbH}$ (Ludwigshafen, 
Table I. Primers sequence used to amplify a partial sequence of the target gene.

\begin{tabular}{|c|c|c|c|c|}
\hline Gene & Accession no. & Primer sequence & Primer position & Band size (bp) \\
\hline Caspase-3 & NM_012922 & $\begin{array}{l}\text { F: 5'-TTGGCTTGTTGAAGGCTACC-3' } \\
\text { R: 5'-GCAGGAGCTTCTGATCTGGT-3' }\end{array}$ & $\begin{array}{l}1,540 \\
1,939\end{array}$ & 400 \\
\hline Gsta2 & NM_017013 & $\begin{array}{l}\text { F: 5'-GGCAAAAGACAGGACCAAAA-3' } \\
\text { R: 5'-GGCTGCAGGAACTTCTTCAC-3' }\end{array}$ & $\begin{array}{l}432 \\
662\end{array}$ & 231 \\
\hline Cat & NM_012520 & $\begin{array}{l}\text { F: 5'-GACACATCCGGGCTCACTAT-3' } \\
\text { R: 5'-GAGCCTAAGCCTGAATGCAC-3' }\end{array}$ & $\begin{array}{l}1,130 \\
1,367\end{array}$ & 238 \\
\hline Sodl & NM_017050 & $\begin{array}{l}\text { F: 5'-CCACTGCAGGACCTCATTTT-3' } \\
\text { R: 5'-CACCTTTGCCCAAGTCATCT-3' }\end{array}$ & $\begin{array}{l}269 \\
484\end{array}$ & 216 \\
\hline$T N F$ & NM_012675 & $\begin{array}{l}\text { F: 5'-ATGGGCTCCCTCTCATCAGT-3' } \\
\text { R: 5'-GGCTGGGTAGAGAACGGATG-3' }\end{array}$ & $\begin{array}{l}341 \\
887\end{array}$ & 547 \\
\hline$I F N-\gamma$ & АH002184 & $\begin{array}{l}\text { F: 5'-TCCCTCCCCACTCCATTAGG-3' } \\
\text { R: 5'-ATTCCTCTGGTCAGCAGCAC-3' }\end{array}$ & $\begin{array}{l}1,130 \\
1,655\end{array}$ & 526 \\
\hline Illa & NM_017019 & $\begin{array}{l}\text { F: 5'-CATGCAGCTCATCATGCTTT-3' } \\
\text { R: 5'-CTTGGGCTCAAAAATGTGGT-3' }\end{array}$ & $\begin{array}{l}1,726 \\
1,897\end{array}$ & 172 \\
\hline$I l 1 b$ & NM_031512 & $\begin{array}{l}\text { F: 5'-AGGCTTCCTTGTGCAAGTGT-3' } \\
\text { R: 5'-TGAGTGACACTGCCTTCCTG-3' }\end{array}$ & $\begin{array}{r}26 \\
255\end{array}$ & 230 \\
\hline Gapdh & NM_017008 & $\begin{array}{l}\text { F: 5'-AGACAGCCGCATCTTCTTGT-3' } \\
\text { R: 5'-TACTCAGCACCAGCATCACC-3' }\end{array}$ & $\begin{array}{c}28 \\
350\end{array}$ & 323 \\
\hline
\end{tabular}

Gsta2, glutathione S-transferase $\alpha 2$; Cat, catalase; Sod1, superoxide dismutase 1; TNF, tumor necrosis factor; IFN, interferon; IL, interleukin.

Germany). Primers sequences and polymerase chain reaction (PCR) product sizes are presented in Table I. The investigated genes included Caspase-3, glutathione S-transferase $\alpha 2$ (Gsta2), catalase (Cat), superoxide dismutase 1 (Sod1), TNF, IFN- $\gamma$, interleukin 1a (Illa) and interleukin $1 \mathrm{~b}(I l l b)$.

Semi-quantitative reverse transcription-PCR (RT-PCR) analysis. Total RNA ( $2 \mu \mathrm{g})$ was reverse transcribed into cDNA using RevertAid First Strand cDNA Synthesis kit (Fermentas; Thermo Fisher Scientific Inc., Waltham, MA, USA). The reaction was incubated for $60 \mathrm{~min}$ at $42^{\circ} \mathrm{C}$ and terminated by heating at $70^{\circ} \mathrm{C}$ for $5 \mathrm{~min}$. Next, $1 \mathrm{ml} \mathrm{cDNA}$ was used for PCR analysis, which was performed using a Perkin Elmer GeneAmp 9600 system (PerkinElmer, Inc., Waltham, MA, USA). The PCR cycling conditions were as follows: Initial cycle of $10 \mathrm{~min}$ at $95^{\circ} \mathrm{C}, 45 \mathrm{sec}$ at $54^{\circ} \mathrm{C}$ and $1 \mathrm{~min}$ at $72^{\circ} \mathrm{C}$; followed by 30 cycles of denaturation at $95^{\circ} \mathrm{C}$ for $1 \mathrm{~min}$, annealing at $54^{\circ} \mathrm{C}$ for $45 \mathrm{sec}$ and extension at $72^{\circ} \mathrm{C}$ for $1 \mathrm{~min}$; and then a final extension step at $72^{\circ} \mathrm{C}$ for $7 \mathrm{~min}$. The total volume of reactions mixture was $25 \mu \mathrm{l}$ and contained 1 unit of AmpliTaq Gold (Applied Biosystems; Thermo Fisher Scientific Inc.), 1X AmpliTaq buffer, $1.5 \mathrm{mM} \mathrm{MgCl}_{2}, 2.5 \mathrm{mM}$ dNTPs and $10 \mathrm{pmol}$ of forward and reverse primers. The expression of Gapdh was detected as a reference value using specific primers (Table I). A negative control containing RNA was used to rule out genomic DNA contamination. The PCR products were confirmed by $2 \%$ agarose gel electrophoresis, and the band density was measured using ImageJ version 1.48 software (http://imagej.nih.gov/ij/).

Histopathological examination. Tissue samples collected from the liver and lungs of rats were fixed in $10 \%$ neutral buffer formalin solution, washed in tap water, dehydrated through an upgraded series of ethanol (50, 70, 80, 90 and 95\%, followed

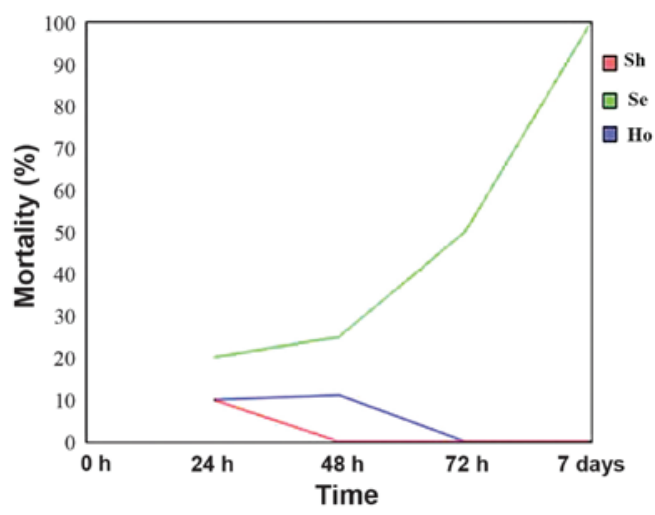

Figure 1. Mortality rate of rats in the sham, sepsis group (cecum ligation and puncture) and septic group treated with Holothuria atra extract (Ho group).

by absolute ethanol)., cleared by xylene and then embedded in paraffin. The paraffin-embedded samples were cut into $5 \mu \mathrm{m}$ sections, which were then routinely stained with hematoxylin and eosin (Sigma-Aldrich, St. Louis, MO, USA) as previously described (43).

Immunohistochemical analysis. The paraffin-embedded samples were cut into $3-\mu \mathrm{m}$ sections and mounted on positively charged slides for caspase-3 immunohistochemical examination. Sections were dewaxed, rehydrated and autoclaved at $95^{\circ} \mathrm{C}$ for $20 \mathrm{~min}$ in antigen retrieval buffer $(10 \mathrm{mM}$ citrate buffer, $\mathrm{pH}$ 6). After washing with phosphate-buffered saline (PBS), endogenous peroxidase was blocked using $3 \% \mathrm{H}_{2} \mathrm{O}_{2}$ in methanol for $15 \mathrm{~min}$. A primary rat-specific antibody for caspase-3 (cat.no. RB-1197-B0,-B1; Thermo Fisher Scientific Inc.) was added following dilution in PBS (1:100), 
A

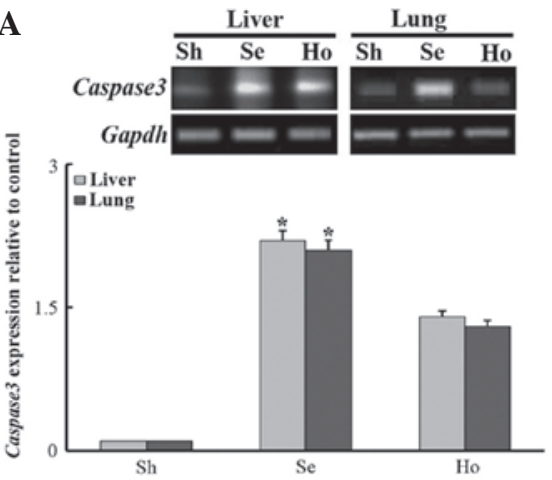

C
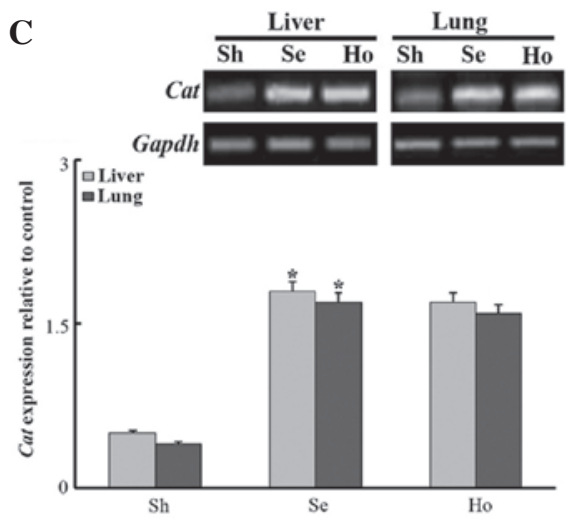

$\mathbf{E}$
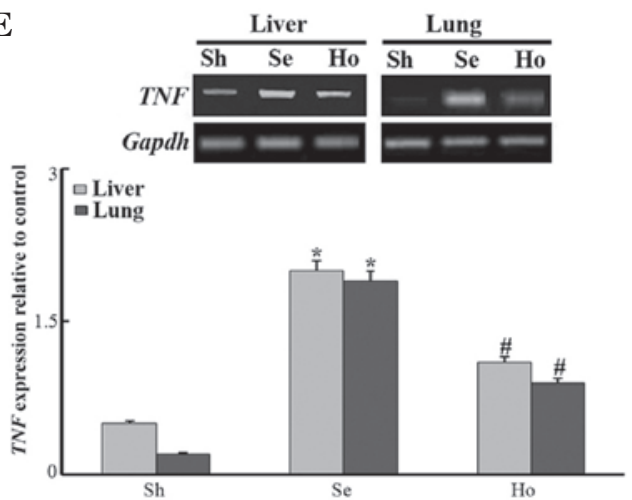

B
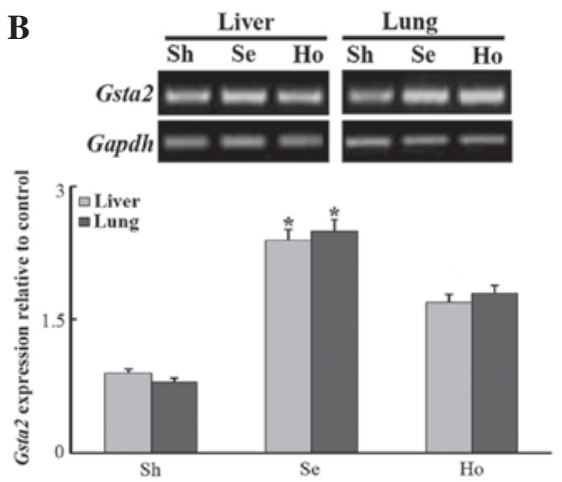

D
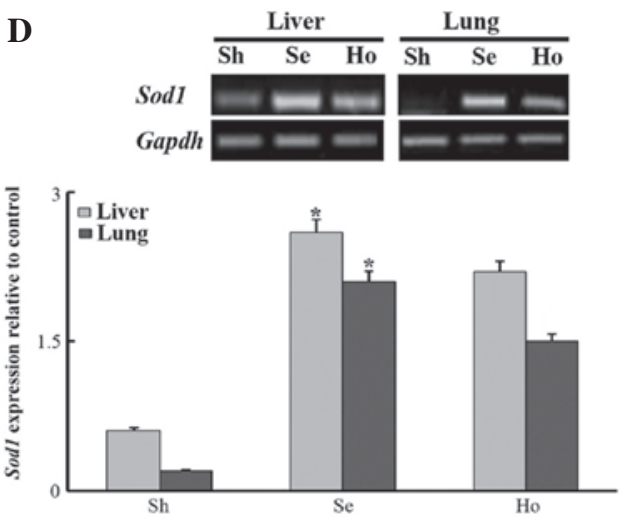

$\mathbf{F}$
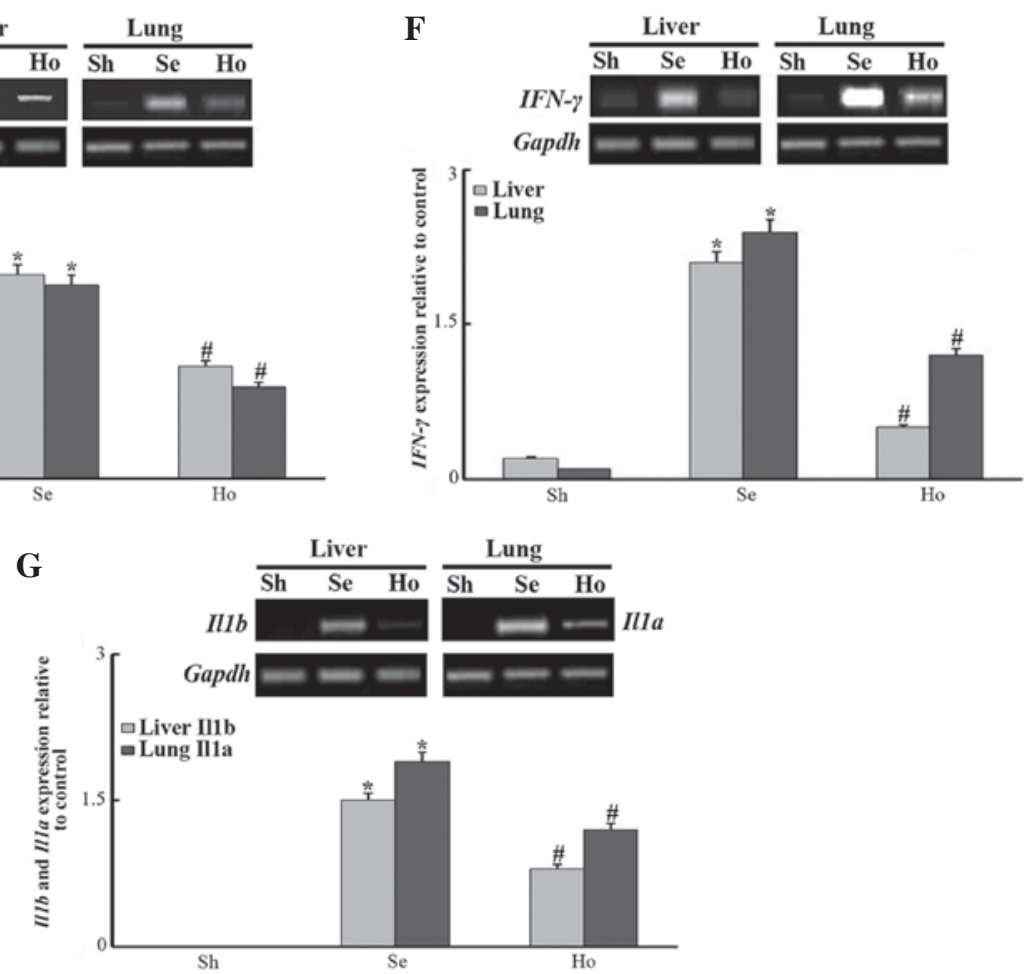

Figure 2. Expression of the responsive genes (A) Caspase-3, (B) Gsta2, (C) Cat, (D) Sod1, (E) TNF and (F) IFN- $\gamma$ in the liver and lung tissues, as well as of (G) $I l l b$ in the liver and Illa in the lung tissues, in Sh, Se and Ho rat groups. Data represent the mean \pm standard error. "P<0.05 vs. Sh group; "P<0.05 vs. Se group. Sh, sham (negative control) group; Se, CLP-induced sepsis group; Ho, sepsis and Holothuria atra extract-treated group; CLP, cecal ligation and puncture; Gsta2, glutathione S-transferase $\alpha 2$; Cat, catalase; Sodl, superoxide dismutase 1; TNF, tumor necrosis factor; IFN, interferon; $I l$, interleukin.

and incubated for $30 \mathrm{~min}$. The slides were then washed three times for 3 min each with PBS. Subsequently, a horseradish peroxidase-conjugated goat anti-mouse IgG secondary antibody (cat. no. 32230; Thermo Fisher Scientific Inc.) was applied to the tissue sections and co-incubated for $30 \mathrm{~min}$.
The slides were washed three times for 3 min each with PBS, and then visualized by adding metal enhanced DAB substrate working solution (Thermo Fisher Scientific Inc.) to the tissues and incubating for $10 \mathrm{~min}$. Next, the slides were washed two times with PBS ( 3 min each time) and then 

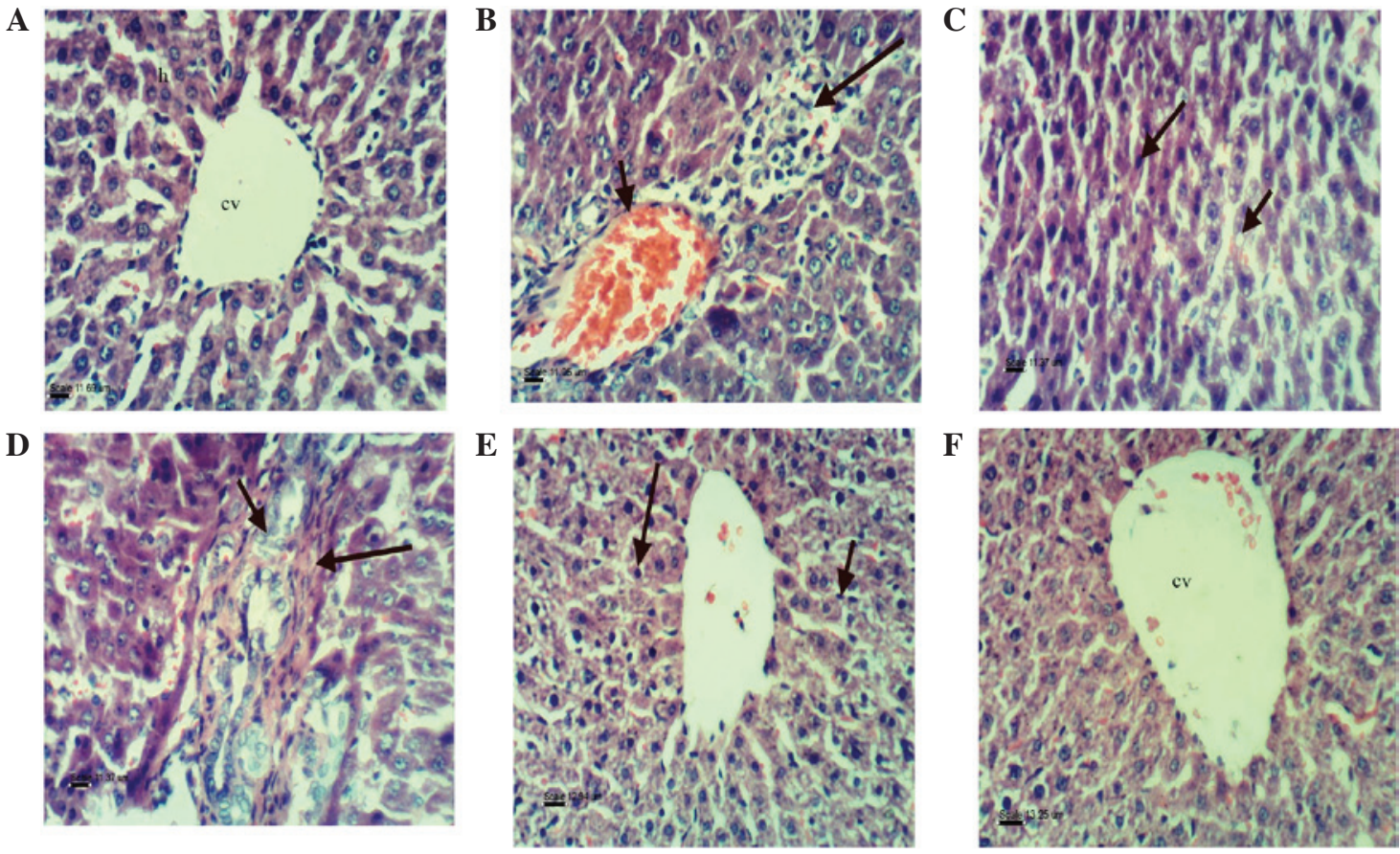

Figure 3. Photomicrograph of rat livers in the various groups: (A) Sham group, showing the normal histological structure of hepatic lobule (bar, $11.69 \mu \mathrm{m}$ ); (B) Se group, showing the congestion of hepatoportal blood vessel, focal hepatic necrosis (short arrow) associated with inflammatory cells infiltration (long arrow; $\mathrm{H} \& \mathrm{E} ;$ bar, $11.05 \mu \mathrm{m}$ ); (C) Se group, showing fatty change of hepatocytes (short arrow) and sporadic necrosis of hepatocytes (long arrow; bar, $11.37 \mu \mathrm{m}$ ); (D) Se group, showing hyperplasia of epithelial lining of the bile duct (short arrow) and fibroplasia in portal tract (long arrow; bar, $11.37 \mu \mathrm{m}$ ); (E) Se group, showing Küpffer cell activation (short arrow) and necrosis of sporadic hepatocytes (long arrow; bar, $12.94 \mu \mathrm{m}$ ); and (F) Sepsis and Holothuria atra extract treatment group, showing apparent normal hepatic parenchyma (bar, $13.25 \mu \mathrm{m}$ ). All stained with hematoxylin-eosin. Se, sepsis group; cv, central vein; h, hepatocyte.

counterstained by adding an adequate amount of hematoxylin to the slide to cover the entire tissue surface (44). The immune reactivity score used to evaluate the intensity of immunohistochemical staining and the proportion of the stained cells was classified as i) absent (0); ii) mild, 25-50\%; and iii) strong, $>50 \%$.

Statistical analysis. The results are expressed as the mean \pm standard error of 10 different rats per group. Statistical analysis was performed with analysis of variance and Fisher's post-hoc test, with $\mathrm{P}<0.05$ considered to indicate statistically significant differences.

\section{Results}

Mortality rate following CLP surgery. At $24 \mathrm{~h}$ after CLP surgery, the rats clearly displayed the sepsis symptoms, such as decreased motor activities, ocular exudates and ruffled fur. In the Sh group, the mortality rate was $10 \%$ at $24 \mathrm{~h}$ decreasing to $0 \%$ after $48 \mathrm{~h}$. In the Se group, the mortality rate was $20 \%$ after $24 \mathrm{~h}$ from CLP surgery, increasing to $100 \%$ after 7 days in comparison with the negative group (Sh). Although the mortality rate was $10 \%$ at $48 \mathrm{~h}$ after the CLP surgery in the Ho-treated group, it decreased to $0 \%$ after $72 \mathrm{~h}$ and remained at this rate until the end of the experiment (Fig. 1).

Molecular detection of gene expression. Eight genes, including Caspase-3, Gsta2, Cat, Sodl, TNF, IFN- $\gamma$, Illb and Illa, were tested for their expression in the liver and lungs of the adult male albino rats in the three groups at 7 days after CLP (Fig. 2), with the expression of Gapdh used as an internal control. As shown in Fig. 2A, the expression of Caspase-3 was found to be significantly increased $(\mathrm{P}<0.05)$ in the liver and lung tissues of the Se group in response to sepsis when compared with the negative control (Sh) tissues; however, the expression was reduced in the Ho group compared with the Se group. In addition, the expression of the antioxidant Gsta2 gene was significantly increased $(\mathrm{P}<0.05)$ in the organs of the Se compared with the Sh group, whilst the Ho group did not display a significant difference compared with the Se group (Fig. 2B), but it was lower in the Ho group. Expression levels of the oxidative stress responsive genes, Cat and Sodl, were increased in the two organs in response to sepsis stress in the Se and Ho groups (Fig. 2C and D). Expression was significantly increased in Se group compared with the Sh group $(\mathrm{P}<0.05)$, whilst the Ho group did not display any significance compared with Se group. Furthermore, the expression levels of anti-inflammatory genes, $T N F$ and $I F N-\gamma$, as well as of the liver tissue-specific Illb and the lung tissue-specific Illa, were significantly increased in the Se group in response to sepsis when compared with the Sh group, whereas the expression of the aforementioned genes was significantly reduced $(\mathrm{P}<0.05)$ in the Ho group, when compared with Se group (Fig. 2E-G). The results indicated that $\mathrm{HaE}$ increased the expression of oxidative stress as well as antioxidant genes, while decreased the expression of apoptotic (Caspase-3), anti-inflammatory (TNF and IFN- $\gamma$ ), interleukins (1a and $1 \mathrm{~b})$ genes in septic rats. This suggests that the extract of sea cucumber H. atra may posses antiseptic and anti-inflammatory properties.

Histopathological examination. The negative control (Sh) group showed normal architecture of the liver, with hepatic 

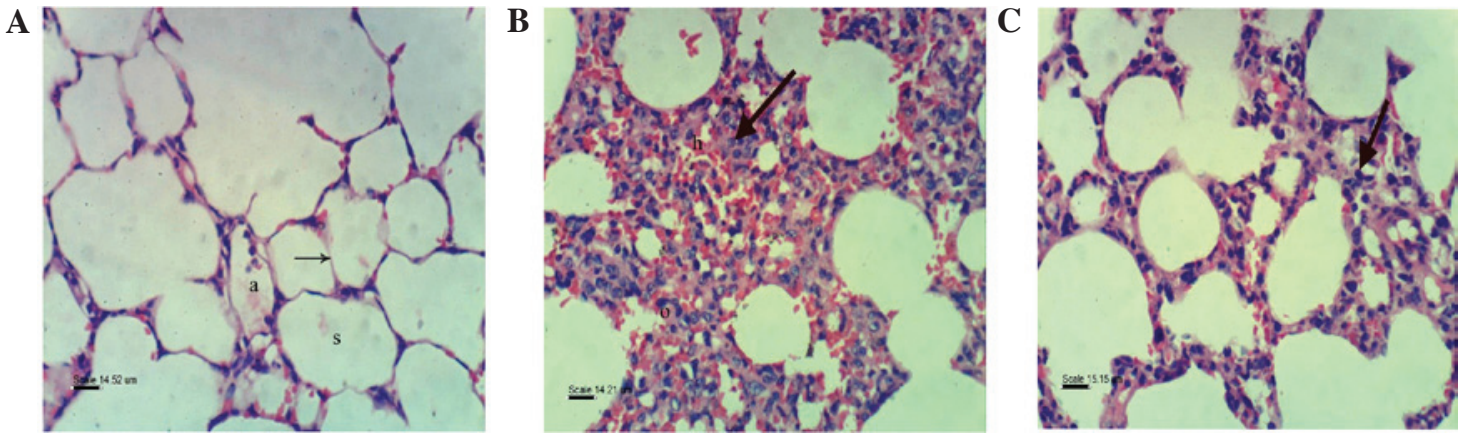

Figure 4. Photomicrograph of rat lung. (A) Sham group, showing the normal histological structure of alveoli (a), alveolar sac (s) and thin alveolar septum (arrow); bar, $14.52 \mu \mathrm{m}$. (B) Septic group, showing interstitial pneumonia characterized by edema (o), hemorrhage (h) and leukocyte infiltration (f); bar, $14.21 \mu \mathrm{m}$. (C) Sepsis and Holothuria atra extract treatment group, revealing slight interstitial pneumonia (arrow); bar, $15.15 \mu$ m. All stained with hematoxylin-eosin.
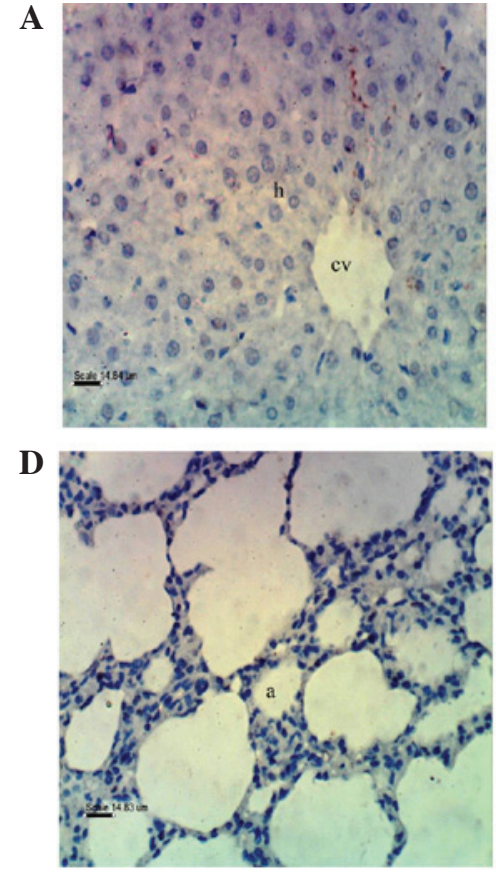
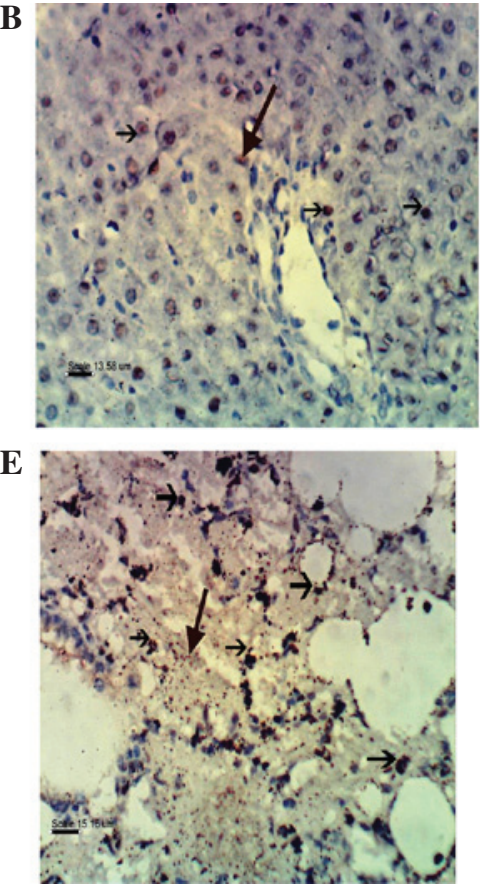
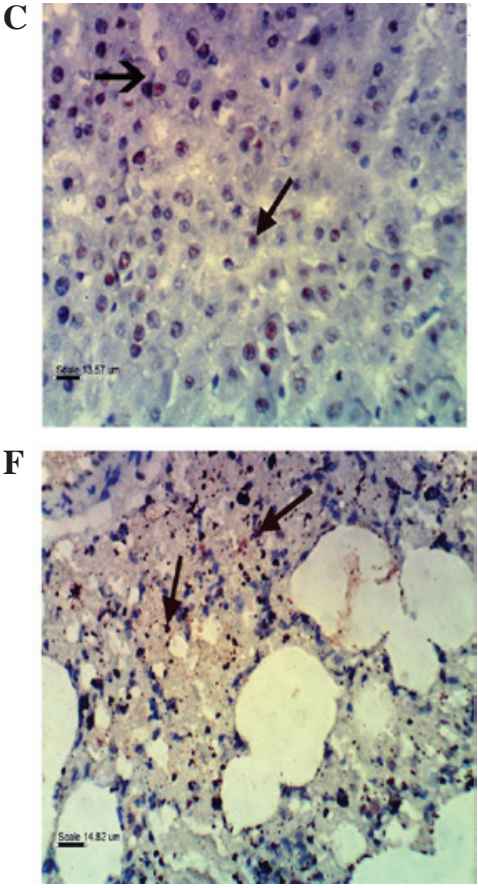

Figure 5. Photomicrograph of immunohistochemical staining of Caspase-3 in rat liver and lungs. Liver tissues: (A) Sham (Sh) group, showing no expression of Caspase-3; bar=14.84 $\mu \mathrm{m}$. (B) Septic (Se) group, showing strong expression of Caspase-3 (arrows); bar=13.58 $\mu \mathrm{m}$. (C) Sepsis and Holothuria atra extract treatment (Ho) group, showing mild expression of Caspase-3 (arrows); bar=13.57 $\mu \mathrm{m}$. Lung tissues: (D) Sh group, showing no expression of Caspase-3; bar=14.83 $\mu \mathrm{m}$. (E) Se group, showing strong expression of Caspase-3 (arrows); bar=15.16 $\mu \mathrm{m}$. (F) Ho group, showing mild expression of Caspase-3 (arrows); bar $=14.82 \mu \mathrm{m}$. cv, central vein; h, hepatocyte; a, alveoli.

lobules around the central vein and each lobule consisting of hepatic cords. The hepatocytes represented the hepatic cords and consisted of polygonal cells with centrally basophilic nuclei and clear acidophilic cytoplasm (Fig. 3A). However, the liver of the Se group presented congestion of the hepatoportal blood vessel, focal hepatic necrosis associated with inflammatory cell infiltration (Fig. 3B), fatty change of hepatocytes, sporadic necrosis of hepatocytes (Fig. 3C), hyperplasia of the epithelial lining of bile duct and fibroplasia in the portal tract (Fig. 3D). In addition, certain examined sections from the Se group showed Küpffer cell activation and necrosis of sporadic hepatocytes (Fig. 3E). By contrast, sections from the Ho group revealed apparent normal hepatic parenchyma (Fig. 3F).

The lung histological examination revealed no evidence of sepsis in the Sh group, which appeared to have a normal structure of alveoli and alveolar sacs with thin alveolar septum (Fig. 4A). By contrast, the lung tissues of the Se group showed marked edema, hemorrhage, leukocyte infiltration and alveolar septal thickening (Fig. 4B), whereas tissue sections from the Ho group presented slight interstitial pneumonia (Fig. 4C).

Immunohistochemistry. Immunohistochemical staining of Caspase- 3 was localized in the nuclei of hepatocytes. The liver tissues of the Sh group showed no expression of Caspase-3 (Fig. 5A), whereas strong expression was observed in the $\mathrm{Se}$ group (Fig. 5B) and moderate expression in the Ho group (Fig. 5C). Upon investigation of lung tissues, the expression of Caspase- 3 was found to be localized in the nuclei of pulmonary cells. The lung tissues of the Sh group showed no expression of Caspase-3 (Fig. 5D), strong expression in the Se group (Fig. 5E) and moderate expression in the Ho group (Fig. 5F). 


\section{Discussion}

H.atra is one of the most important species in the sea cucumber family, and it is found worldwide, including in the Red Sea region $(40,45,46)$. The extract of $H$. atra has been evaluated for the presence of bioactive compounds and its various biological activities (47). In the present study, the administration of $\mathrm{HaE}$ was found to reduce the mortality rate in the CLP rats (Ho group), which was evidently elevated in the CLP rats that did not receive $\mathrm{HaE}$ (Se group). The decrease in sepsis-induced mortality upon $\mathrm{HaE}$ treatment can be explained according to the findings of Dhinakaran and Lipton (47), who stated that the extract of sea cucumber has antimicrobial activity. The Se group exhibited molecular and histopathological changes in the liver and lung tissues, which were characterized by increased expression of oxidative stress, antioxidant and anti-inflammatory genes, as well as a congestion of the hepatoportal blood vessel and focal hepatic necrosis associated with inflammatory cell infiltration. The Se rat lungs showed marked edema, hemorrhage and alveolar septal thickening, and these findings agreed with the observations of Ates et al (10), Esmat et al (48) and Baiomy and Saad (49).

The expression levels of oxidative stress and antioxidant genes can be used as markers to detect the response to microbial infection (50). The administration of HaE upregulated the expression of the antioxidant gene Gsta2, as well as of the oxidative stress responsive genes, Cat and Sodl. In addition, HaE administration downregulated the anti-inflammatory genes $T N F, I F N-\gamma$, liver $I l I b$ and lung Ill $a$, and these results were in agreement with previous observation (29-31). Furthermore, these findings were confirmed by histopathological analysis in the current study, which showed apparent normal hepatic parenchyma and slight interstitial pneumonia in the Ho group.

Several studies have previously reported that TNF and IFN- $\gamma$ are involved in the development of septic shock (12-20,38). Interleukins $1 \mathrm{~A}$ and $1 \mathrm{~B}$, two members of interleukin-1 family (51), are also involved in sepsis. IL1A is responsible for the production of inflammation, as well as the promotion of fever and sepsis (52), while IL1B is involved in a variety of cellular activities, including cell proliferation, differentiation and apoptosis (53). Based on the present study results, we can speculate that the antimicrobial activity of $\mathrm{HaE}$ resulted in a decrease in sepsis, and consequently the expression levels of $T N F$ and $I F N-\gamma$ were reduced.

Various studies have investigated the effects of the sea cucumber components, including polysaccharides, which exhibited a variety of biological activities, such as anti-tumor (54), anti-oxidation $(55,56)$ and anti-apoptotic $(35)$ activities. Chenghui et al (57) and Chen et al (58) investigated the antioxidant properties of peptides and hydrolysates extracted from different species of sea cucumbers and found that hydrolysates have a considerable antioxidant activity, which may be associated with the presence of antioxidant peptides. In addition, it was reported that the presence of the active phenolic compounds in the body wall of the sea cucumbers may be due to phenolic-rich materials, such as phytoplankton and particles derived from degrading marine macroalgae, which are the main sources of food for sea cucumbers $(59,60)$. Furthermore, the body wall of sea cucumber contains chlorogenic acid, which has been found to have a potential hepatoprotective effect in several animal models of liver injury (61).

The results of the present study showed that the expression of Caspase-3 gene, which was highly elevated in Se group, was decreased in response to administration of $\mathrm{HaE}$ in the Ho group. This finding was supported by the immunohistochemical staining of Caspase-3 in liver and lung tissues, showing no expression of Caspase- 3 in the Sh group, strong expression in the Se group and moderate sexpression in the Ho group; these findings coincided with the observations of $\mathrm{Hu}$ et al (62). According to the analysis of these data at gene expression and histopathological levels, we speculate that the beneficial effect of $\mathrm{HaE}$ of sea cucumber against sepsis may be attributed to its antioxidant components and antiapoptotic activity. Thus, HaE may be a potential functional agent for the improvement of survival in sepsis.

In conclusion, the data presented in the current study indicated that $\mathrm{HaE}$ is a useful natural product that is able to mitigate the liver and lung damages resulting from induced sepsis by CLP. It possesses antioxidant, antitumor and antiapoptotic activities. The fact that the Ho group revealed apparent normal hepatic and lung parenchyma may be attributed to its antioxidant components, where necrosis and congestion decreased, which may also be attributed to its anti-inflammatory and antiapoptotic activities. Purification and identification of these structures in future studies is warranted.

It appears that with further research in this field, the extracts of marine organisms, including those of sea cucumbers, may be used as antiseptic, antioxidant, antitumor and antiapoptotic agents.

\section{References}

1. Raoofi R, Salmani Z, Moradi F, Sotoodeh A and Sobhanian S: Procalcitonin as a marker for early diagnosis of sepsis. Am J Infect Dis 10: 15-20, 2014.

2. Ma N, Xing C, Xiao H, Wang Y, Wang K, Hou C, Han G, Chen G, Marrero B, Wang Y, et al: C5a regulates Il- $12^{+}$DC migration to induce pathogenic Th1 and Th17 cells in sepsis. PLoS One 8: e69779, 2013.

3. Galley HF: Oxidative stress and mitochondrial dysfunction in sepsis. Br J Anaesth 107: 57-64, 2011.

4. Abuşoğlu S, Onur E, Çelik Ht, Güvenç Y, Sakarya M, Sakarya A, Var A and Uyanik BS: The effect of lidocaine on liver tissue lipid peroxide levels in septic rat model. Int J Mevlana Med Sci 1: 31-34, 2013.

5. Mansour AA, Salam MA and Saad YM: Mice (Mus musculus) genome responses to methotrexate (MTX) and some plant extracts. Life Sci J 9: 4881-4886, 2012.

6. Bergquist M, Nurkkala M, Rylander C, Kristiansson E, Hedenstierna $\mathrm{G}$ and Lindholm C: Expression of the glucocorticoid receptor is decreased in experimental Staphylococcus aureus sepsis. J Infect 67: 574-583, 2013.

7. Hill AL, Lowes DA, Webster NR, Sheth CC, Gow NA and Galley HF: Regulation of pentraxin-3 by antioxidants. Br J Anaesth 103: 833-839, 2009.

8. Nesseler N, Launey Y, Aninat C, Morel F, Mallédant Y and Seguin P: Clinical review: The liver in sepsis. Crit Care 16: 235, 2012.

9. Ozturk E, Demirbilek S, Begec Z, Surucu M, Fadillioglu E, Kirimlioglu $\mathrm{H}$ and Ersoy MO: Does leflunomide attenuate the sepsis-induced acute lung injury? Pediatr Surg Int 24: 899-905, 2008.

10. Ates I, Dogan N, Aksoy M, Halıcı Z, Gündogdu C and Keles MS: The protective effects of IgM-enriched immunoglobulin and erythropoietin on the lung and small intestine tissues of rats with induced sepsis: Biochemical and histopathological evaluation. Pharm Biol 53: 78-84, 2015. 
11. Edelman DA, Jiang Y, Tyburski JG, Wilson RF and Steffes CP Cytokine production in lipopolysaccharide-exposed rat lung pericytes. J Trauma 62: 89-93, 2007.

12. Spooner CE, Markowitz NP and Saravolatz LD: The role of tumor necrosis factor in sepsis. Clin Immunol Immunopathol 62 S11-S17, 1992.

13. Suk K, Chang I, Kim YH, Kim S, Kim JY, Kim H and Lee MS: Interferon gamma (IFNgamma) and tumor necrosis factor alpha synergism in ME-180 cervical cancer cell apoptosis and necrosis IFNgamma inhibits cytoprotective NF-kappa B through STAT1/IRF-1 pathways. J Biol Chem 276: 13153-13159, 2001.

14. Price G, Brenner MK, Prentice HG, Hoffbrand AV and Newland AC: Cytotoxic effects of tumour necrosis factor and gamma-interferon on acute myeloid leukaemia blasts. Br J Cancer 55: 287-290, 1987.

15. Pasparakis M, Alexopoulou L, Episkopou V and Kollias G: Immune and inflammatory responses in TNF alpha-deficient mice: A critical requirement for TNF alpha in the formation of primary B cell follicles, follicular dendritic cell networks and germinal centers and in the maturation of the humoral immune response. J Exp Med 184: 1397-1411, 1996.

16. Rothe J, Lesslauer W, Lötscher H, Lang Y, Koebel P, Althage A, Zinkernagel R, Steinmetz M, Bluethmann $\mathrm{H}$ and Köntgen F: Mice lacking the tumour necrosis factor receptor 1 are resistant to TNF-mediated toxicity but highly susceptible to infection by Listeria monocytogenes. Nature 364: 798-802, 1993.

17. Lv S, Han M, Yi R, Kwon S, Dai C and Wang R: Anti-TNF- $\alpha$ therapy for patients with sepsis: A systematic meta-analysis. Int J Clin Pract 68: 520-528, 2014.

18. Doherty DE and Worthen GS: Lipopolysaccharide-induced monocyte retention in the lungs of rabbits. Role of cell stiffness and the CD11/CD18 leukocyte adhesion complex. Chest 105 (3 Suppl): 108S, 1994.

19. Silva AT and Cohen J: Role of interferon-gamma in experimental gram-negative sepsis. J Infect Dis 166: 331-335, 1992.

20. Car BD, Eng VM, Schnyder B, Ozmen L, Huang S, Gallay P, Heumann D, Aguet $M$ and Ryffel B: Interferon gamma receptor deficient mice are resistant to endotoxic shock. J Exp Med 179: 1437-1444, 1994

21. Heinzel FP: The role of IFN-gamma in the pathology of experimental endotoxemia. J Immunol 145: 2920-2924, 1990.

22. Boehm U, Klamp T, Groot M and Howard JC: Cellular responses to interferon-gamma. Annu Rev Immunol 15: 749-795, 1997.

23. Shtrichman R and Samuel CE: The role of gamma interferon in antimicrobial immunity. Curr Opin Microbiol 4: 251-259, 2001

24. Heremans H, Van Damme J, Dillen C, Dijkmans R and Billiau A: Interferon gamma, a mediator of lethal lipopolysaccharide-induced Shwartzman-like shock reactions in mice. J Exp Med 171: 1853-1869, 1990

25. Bosisio D, Polentarutti N, Sironi M, Bernasconi S, Miyake K, Webb GR, Martin MU, Mantovani A and Muzio M: Stimulation of toll-like receptor 4 expression in human mononuclear phagocytes by interferon-gamma: A molecular basis for priming and synergism with bacterial lipopolysaccharide. Blood 99. 3427-3431, 2002.

26. Adib-Conquy M and Cavaillon JM: Gamma interferon and granulocyte/monocyte colony-stimulating factor prevent endotoxin tolerance in human monocytes by promoting interleukin-1 receptor-associated kinase expression and its association to MyD88 and not by modulating TLR4 expression. J Biol Chem 277: 27927-27934, 2002.

27. Ridzwan BH, Kaswandi MA, Azman Y and Fuad M: Screening for antibacterial agents in three species of sea cucumbers from coastal areas of Sabah. Gen Pharmacol 26: 1539-1543, 1995.

28. Selva Prabhu A, Ananthan G, Mohamed Hussain HS and Balasubramanian T: Antibacterial activity of Ascidian phallusia arabica against human clinical isolates. J Appl Pharmaceutical Sci 1: 143-145, 2011

29. Sohair F, Mahmoud AA and Mohannad H: Ameliorative effect of the sea cucumber Holothuria arenicola extract against gastric ulcer in rats. J Basic Appl Zoology 72: 16-25, 2015.

30. Dakrory AI, Fahmy SR, Soliman AM, Mohamed AS and Amer SA: Protective and curative effects of the sea cucumber Holothuria atra extract against DMBA-induced hepatorenal diseases in rats. Biomed Res Int 2015: 563652, 2015.

31. Yahyavi M, Afkhami M, Mokhleci A, Ehsanpour M, Khazaali1 A, Khoshnood R and Jvadi A: Fatty acid in local sea cucumber species from Persian Gulf (Qeshm island). Ann Biol Res 3: 3597-3601, 2012
32. Coopersmith CM, Chang KC, Swanson PE, Tinsley KW, Stromberg PE, Buchman TG, Karl IE and Hotchkiss RS: Overexpression of Bcl-2 in the intestinal epithelium improves survival in septic mice. Crit Care Med 30: 195-201, 2002.

33. Coopersmith CM, Stromberg PE, Dunne WM, Davis CG, Amiot DM II, Buchman TG, Karl IE and Hotchkiss RS: Inhibition of intestinal epithelial apoptosis and survival in a murine model of pneumonia-induced sepsis. JAMA 287: 1716-1721, 2002.

34. Oliver L and Vallette FM: The role of caspases in cell death and differentiation. Drug Resist Updat 8: 163-170, 2005.

35. Nishikawa Y, Furukawa A, Shiga I, Muroi Y, Ishii T, Hongo Y, Takahashi S, Sugawara T,Koshino H and Ohnishi M: Cytoprotective effects of lysophospholipids from sea cucumber holothuria atra. PLoS One 10: e135701, 2015.

36. Nemzek JA, Hugunin KMS and Opp MR: Modeling sepsis in the laboratory: Merging sound science with animal well-being. Comp Med 58: 120-128, 2008.

37. Ercan M and Ozdemir S: The contribution to studies of the effect of $\beta$-glucan on plasma viscosity in a rat sepsis model. Med Sci Disc 2: 148-153, 2015.

38. Chien WS, Chen YH, Chiang PC, Hsiao HW, Chuang SM, Lue SI and Hsu C: Suppression of autophagy in rat liver at late stage of polymicrobial sepsis. Shock 35: 506-511, 2011.

39. Lo S, Yuan SS, Hsu C, Cheng YJ, Chang YF, Hsueh HW, Lee PH and Hsieh YC: Lc3 over-expression improves survival and attenuates lung injury through increasing autophagosomal clearance in septic mice. Ann Surg 257: 352-363, 2013.

40. Purcell SW, Samyn Y and Conand C: Commercially important sea cucumbers of the world. FAO Species Catalogue for Fishery Purposes No. 6. Food and Agriculture Organization, Rome, 2012.

41. Adibpour N, Nasr F, Nematpour F, Shakouri A and Ameri A: Antibacterial and antifungal activity of Holothuria leucospilota isolated from Persian Gulf and Oman sea. Jundishapur J Microbiol 7: e8708, 2014.

42. Attia HF, Kandiel MM, Ismail TA, Soliman MM, Nassan MA and Mansour AA: Immunohistochemical, cellular localization and expression of inhibin hormone in the buffalo (Bubalus bubalis) adenohypophysis at different ages. J Vet Anat 5: 83-104, 2012.

43. Bancroft JD, Cook HC and Turner DR: Manual of histological techniques and their diagnostic application. 2nd edition. Churchill Livingstone, London, 1994.

44. Zarnescu O, Brehar FM, Chivu M and Ciurea AV: Immunohistochemical localization of caspase-3, caspase-9 and Bax in U87 glioblastoma xenografts. J Mol Histol 39: 561-569, 2008.

45. Toral-Granda V, Lovatelli A and Vasconcellos M: Sea cucumbers - A global review of fisheries and trade. FAO Fisheries and Aquaculture Technical Paper 516. Food and Agriculture Organization, Rome, 2008.

46. Hasan MH: Stock assessment of holothuroid populations in the Red Sea waters of Saudi Arabia. In: SPC Beche-de-mer Information Bulletin 29. Eeckhaut I (ed). Secretariat of the Pacific Community, Nouméa, pp 31-37, 2009.

47. Dhinakaran DI and Lipton AP: Bioactive compounds from Holothuria atra of Indian ocean. Springerplus 3: 673, 2014.

48. Esmat AY, Said MM, Soliman AA, El-Masry KS and Badiea EA: Bioactive compounds, antioxidant potential and hepatoprotective activity of sea cucumber (Holothuria atra) against thioacetamide intoxication in rats. Nutrition 29: 258-267, 2013.

49. Baiomy A and Saad D: Histopathological and immunohistochemical studies of antiseptic effect of Sepia officinalis against induced sepsis in male albino rats (Rattus norvegicus). World J Med Sci 12: 303-315, 2015.

50. Rahal A, Kumar A, Singh V, Yadav B, Tiwari R, Chakraborty S and Dhama K: Oxidative stress, prooxidants and antioxidants: The interplay. Biomed Res Int 2014: 761264, 2014

51. March CJ, Mosley B, Larsen A, Cerretti DP, Braedt G, Price V, Gillis S, Henney CS, Kronheim SR and Grabstein K: Cloning, sequence and expression of two distinct human interleukin-1 complementary DNAs. Nature 315: 641-647, 1985.

52. Bankers-Fulbright JL, Kalli KR and Mckean DJ: Interleukin-1 signal transduction. Life Sci 59: 61-83, 1996.

53. Wang Q, Zhang H, Zhao B and Fei H: IL-1beta caused pancreatic beta-cells apoptosis is mediated in part by endoplasmic reticulum stress via the induction of endoplasmic reticulum $\mathrm{Ca}^{2+}$ release through the c-Jun N-terminal kinase pathway. Mol Cell Biochem 324: 183-190, 2009,

54. Jiao L, Li X, Li T, Jiang P, Zhang L, Wu M and Zhang L: Characterization and anti-tumor activity of alkali-extracted polysaccharide from Enteromorpha intestinalis. Int Immunopharmacol 9: 324-329, 2009. 
55. Zhong Y, Khan MA and Shahidi F: Compositional characteristics and antioxidant properties of fresh and processed sea cucumber (Cucumaria frondosa). J Agric Food Chem 55: 1188-1192, 2007.

56. da Silva Gomes EC, Jimenez GC, da Silva LC, de Sá FB, de Souza KP, Paiva GS and de Souza IA: Evaluation of antioxidant and antiangiogenic properties of caesalpinia echinata extracts. J Cancer 5: 143-150, 2014.

57. Chenghui L, Beiwei Z, Xiuping D and Liguo C: Study on the separation and antioxidant activity of enzymatic hydrolysates from sea cucumber. Food Ferment Ind 33: 50-53, 2007.

58. Chen Y, Miao Y, Huang L, Li J, Sun H, Zhao Y, Yang J and Zhou W: Antioxidant activities of saponins extracted from Radix trichosanthis: An in vivo and in vitro evaluation. BMC Complement Altern Med 14: 1-8, 2014.
59. LiSP,Zhao KJ,JiZN, SongZH,Dong TT,Lo CK, Cheung JK,Zhu SQ and Tsim KW: A polysaccharide isolated from Cordyceps sinensis, a traditional Chinese medicine, protects $\mathrm{PC} 12$ cells against hydrogen peroxide-induced injury. Life Sci 73: 2503-2513, 2003.

60. Althunibat OY, Hashim RB, Taher M, Daud JM, Ikeda MA and Zali BI: In vitro antioxidant and antiproliferative activities of three Malaysian sea cucumber species. Eur J Sci Res 37: 376-387, 2009.

61. Xu Y, Chen J, Yu X, Tao W, Jiang F, Yin Z and Liu C: Protective effects of chlorogenic acid on acute hepatotoxicity induced by lipopolysaccharide in mice. Inflamm Res 59: 871-877, 2010.

62. Hu TJ, Wei XJ, Zhang X, Cheng FS, Shuai XH, Zhang L and Kang L: Protective effect of Potentilla anserine polysaccharide (PAP) on hydrogen peroxide induced apoptosis in murine splenic lymphocytes. Carbohyd Polym 79: 356-361, 2010. 